\title{
Production of Tachidius discipes (Copepoda: Harpacticoida)
}

\author{
Peter M. J. Herman, Carlo Heip and Bernadette Guillemijn
}

Marine Biology Section, Zoology Institute, State University of Gent, Ledeganckstraat 35, B-9000 Gent, Belgium

\begin{abstract}
The secondary production of the harpacticoid copepod Tachidius discipes Giesbrecht 1881 was estimated during spring 1979. The population was sampled every $3 \mathrm{~d}$. Three generation peaks were observed. These were clearly distinct in the first copepodite stages, but gradually showed more overlap in older stages. Production of copepodites and adults was estimated in 2 ways: (1) Peaks were separated and the forward shifting of peaks in consecutive stages was used to estimate stage durations; (2) the size-frequency method was applied. Both estimates of the production of copepodites and adults are in good agreement: $1.10 \mathrm{~g} \mathrm{dwt} \mathrm{m}^{-2}$ and $1.02 \mathrm{~g} \mathrm{dwt} \mathrm{m}^{-2}$. Egg production amounts to $0.31 \mathrm{~g} \mathrm{dwt} \mathrm{m} \mathrm{m}^{-2}$; naupliar production is roughly estimated at $1.11 \mathrm{~g} \mathrm{dwt} \mathrm{m} \mathrm{m}^{-2}$. The production efficiency, $\mathrm{P} /(\mathrm{P}+\mathrm{R})$, of copepodites and adults is 0.36 ; for the total population it is 0.43 . This value corresponds well to the value estimated from culture experiments with this population.
\end{abstract}

\section{INTRODUCTION}

Meiobenthic populations are among the least studied from the point of view of energetics. Only recently have papers appeared dealing with direct production estimates of field populations of meiobenthic crustaceans (Feller, 1982; Fleeger and Palmer, 1982). The limited information available reveals that the productivity (measured by yearly production/ biomass rates, $\mathrm{P} / \mathrm{B}$ ) of meiobenthic populations can differ widely from the speculative and often used value $\mathrm{P} / \mathrm{B}=9$. This value was proposed by Gerlach (1971), based on the life cycle characteristics of 2 nematode species. Whereas the use of a single $P / B$ value for all populations is not advisable, the scaling of $\mathrm{P} / \mathrm{B}$ by body mass (Banse and Mosher, 1980) may be more useful (Heip et al., 1982). This scaling reveals a remarkable pattern, already anticipated by Banse and Mosher (1980), in that the P/B-body weight line for meiobenthic populations lies considerably lower than would be expected from the extrapolation of values for larger organisms. The scaling of the intrinsic rate of natural increase $\mathrm{r}_{\mathrm{m}}$ by body weight (Banse, 1982) corroborates this observation, since both $I_{m}$ and $\mathrm{P} / \mathrm{B}$ are highly correlated with the generation time, and thus with each other.
Not only are $\mathrm{P} / \mathrm{B}$ and $\mathrm{I}_{\mathrm{m}}$ relatively lower in meiobenthic populations, the review of Banse (1982) also shows that the respiration rate of meiofauna is lower than would be expected from extrapolation from the respiration of larger organisms. We could confirm this trend for 1 ostracod (Herman and Heip, 1982) and 5 copepod species (Herman and Heip, 1983) from a brackish water habitat. The low respiration rate of the ostracod Cyprideis torosa explains why the production efficiency $(\mathrm{P} /[\mathrm{P}+\mathrm{R}])$ of this slow-growing species is almost equal to the mean value for non-insect detritivores given by Humphreys (1979) (Herman et al., 1983). The question of production efficiencies in meiobenthic populations is not at all settled. Several studies on nematodes (Schiemer et al., 1980; Warwick, 1981; Schiemer, 1982a, b) yielded extremely high values for the production efficiency, one value even exceeding $90 \%$.

For the harpacticoid copepod Tachidius discipes, Warwick (1981) calculated a production efficiency of ca. $70 \%$. His calculation was based on field data from the 'Dievengat', a brackish water pond in northern Belgium (Heip and Smol, 1976; Heip, 1977), and from respiration measurements of copepods from the Lynher estuary (S.W. England) (Teare and Price, 1979). Elsewhere we show that there is a considerable difference 
in respiration rates between the 2 populations of this species examined (Herman and Heip, 1983). In this paper we treat in more detail the production of the Dievengat population so that a more accurate calculation of the production efficiency is possible.

Tachidius discipes is a widely distributed member of estuarine meiofauna (Muus, 1967). In the community we studied, it typically occurs in large numbers during spring (Heip, 1979; Herman and Heip, in press). Maximum densities are ca. 100,000 individuals $\mathrm{m}^{-2}$, one peak value exceeding 300,000 ind $\mathrm{m}^{-2}$. The species lives epibenthically and feeds on benthic microalgae.

\section{MATERIAL AND METHODS}

During spring 1979 (March-June), a population of Tachidius discipes was studied in a $10 \mathrm{~cm}$ deep brackish water pond, the 'Dievengat', northern Belgium. Salinity fluctuated between 11 and $16 \%$ (mean: $14.6 \%$ ) during the period of investigation. The sediment is a well-sorted fine sand (median grain size $0.223 \mathrm{~mm}$ ), covered with large amounts of detritus.

Samples were taken every $3 \mathrm{~d}$ with a $6.06 \mathrm{~cm}^{2}$ glass corer, to a depth of $5 \mathrm{~cm}$, and fixed in a neutral $4 \%$ formaldehyde solution, heated to $70^{\circ} \mathrm{C}$. The copepods were extracted from the sediment as described by Heip et al. (1974), except that centrifugation of the finer fractions was done with LUDOX, a silica-gel, instead of sucrose (De Jonge and Bouwman, 1977).

It was impossible to sample the nauplii quantitatively in this detritus-rich sediment. Copepodites and adults were extracted with high efficiency. On each date the number of copepods in each developmental stage (from Cop I to adult) was recorded. The descriptions of the copepodites of Tachidius discipes by Teare (1978) were used.

Dry weights were deternined on a Mettler ME22 microbalance to a precision of $\pm 1 \mu \mathrm{g}$. Batches of 50 to 100 individuals belonging to the same developmental stage were dried for $2 \mathrm{~h}$ at $110^{\circ} \mathrm{C}$ before weighing.

In order to suppress the random variation ('noise') in the density data, a weighted running mean was applied with length 3 and weight factors $0.23,0.54$, 0.23 (Velleman, 1977). Inspection of the density curves of the 6 developmental stages revealed the existence of several peaks which can be interpreted as representing separate generations. These peaks are well separated in the first stages, but become gradually less distinct and more overlapping in the older ones. In order to separate them we used a method devised for splitting statistical frequency distributions into Gaussian components (Bhattacharya, 1967). In this method the mean and variance of the constituting Gaussians are determined graphically on a plot of $\ln \left(Y_{1+1} / Y_{i}\right)$ against $X_{i}$ (where $X_{i}$ is the class midpoint of the $i$-th class, and $Y_{i}$ the corresponding frequency). The abso-

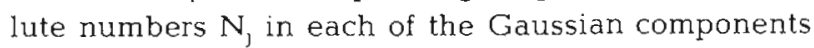
are determined by solving a system of $\mathrm{k}$ equations ( $\mathrm{k}$ being the number of Gaussians). This gives a good fit, although it does not consider error terms explicitly (Bhattacharya, 1967).

The results of this analysis can be used for a production estimate with the method of Rigler and Cooley (1974): the means of the Gaussian components correspond to their 'mean pulse time' of the peaks, and the numbers $\mathrm{N}_{\mathrm{j}}$ to the surfaces under a peak's curve. For each generation the production is estimated as:

$P=\sum_{i=1}^{5}\left(\frac{N_{i+1}}{D_{1+1}}-\frac{N_{i}}{D_{i}}\right) \times\left(W_{i+1} W_{1}\right)^{1 / 2}$

where $i=$ stage number; $D_{i}=$ duration (days) of the stage $i ; N_{i} / D_{i}=$ number of copepods in the stage.

As an independent test of the whole procedure we also estimated the production with the size-frequency method, as modified for the analysis of populations grouped in developmental stages by Herman et al. (1983). This method gives an approximation of the relative duration of each stage (giving Stage I the arbitrary duration of 1) by assuming exponential mortality. In the case of Tachidius discipes we also need an estimate of the relative duration of egg + naupliar stages. This is provided by culture experiments of Smol and Heip (1974) from which it can be concluded that this duration is $3 / 4$ of the copepodite stages combined. The method further requires only an estimate of the number of generations occurring during the study period, which in this case is 3 .

The number of eggs produced was calculated from the observed density of females carrying eggs by the formula:

$$
N_{e}=\sum_{t} \frac{N_{t} \times C}{T_{t}} \times E
$$

where summation is over all sampling dates $t_{i} c=i n-$ terval (days) between 2 samplings; $T_{t}=$ embryonic development time at the prevailing temperature at time $t_{;} E=$ number of eggs per egg sac. Both $T_{t}$ and $E$ are available from culture experiments by Smol and Heip (1974) and Heip and Smol (1976).

This estimate of the number of eggs produced allows a rough calculation of the naupliar production. Assuming that within the naupliar phase both growth and mortality are exponential, we have:

$$
\begin{aligned}
& W_{t}=W_{0} e^{G t} \\
& N_{t}=N_{0} e^{-Z t}
\end{aligned}
$$

where $\mathrm{G}$ and $\mathrm{Z}=$ instantaneous growth and mortality rates, respectively. 
Production is given by Allen (1971) as:

$$
P=(G /[G-Z])\left(N_{T} W_{T}-N_{0} W_{o}\right)
$$

where $N_{0}, W_{0}, N_{T}, W_{T}=$ numbers present and individual weight at times o and $T$, respectively. We estimated $W_{0}$ as the weight of an egg, and $W_{T}$ as the weight of a Copepodite I. $N_{\Upsilon}$ is the number entering the Copepodite I stage, and $N_{0}$ is the number of eggs produced. G and $Z$ can be calculated from Eq. (3) and (4), provided an estimate of $T$ is available. An estimate of $G$, and thus of $T$ is necessary for the biomass integral (see below), but for the production estimation by Eq. (5) it is sufficient to estimate GT and ZT, since the factor $T$ disappears in the division $G /(G-Z)$. GT and $Z T$ are estimated as $\ln \left(\mathrm{W}_{\mathrm{T}} / \mathrm{W}_{\mathrm{o}}\right)$ and $-\ln \left(\mathrm{N}_{\mathrm{T}} / \mathrm{N}_{\mathrm{o}}\right)$, respectively.

One complication arises because this estimate of naupliar production is based on the growth increment principle, whereas the production of copepodites is based on the principle of summation of elimination (see Heip et al., 1982 for a discussion). As a consequence of this difference, it can be seen that the production of Copepodite I is calculated twice. As this production belongs most logically to the naupliar stage, it is subtracted from the copepodite production for the calculation of production efficiency.

In order to estimate the mean biomass of the nauplii we use the relation (Allen, 1971)

$$
\mathrm{P} / \mathrm{B}^{\mathrm{x}}=\mathrm{G}
$$

which is valid in the case of exponential growth and mortality. Here $\mathrm{B}^{\mathrm{x}}=$ biomass - integral:

$$
B^{x}=\int_{0}^{T} N_{t} W_{t} d t
$$

Once $\mathrm{B}^{\mathrm{x}}$ is known for the nauplii, the calculation of the mean biomass of the total population is straightforward.

The mean respiration of the different stages of copepodites and adults at $20{ }^{\circ} \mathrm{C}$ was determined by Herman and Heip (1983) with Cartesian Diver microrespirometry. The respiration-body weight relation was given by $\mathrm{R}=13.18 \mathrm{~W}^{0.82}$, with $\mathrm{R}$ in $\mathrm{nl} \mathrm{O} \mathrm{O}_{2}$ ind. ${ }^{-1} \mathrm{~h}^{-1}$, and $W$ in $\mu \mathrm{g}$ dwt. Total population respiration was calculated from these values after adjustment for temperature in the field with Krogh's normal curve (Winberg, 1971). The production efficiency was calculated directly for copepodites and adults.

Respiration of nauplli was estimated in the following way. Assuming exponential growth and mortality (cf. above) we have at any time $t: W_{t}=W_{0} e^{G t}$ and from $\mathrm{R}_{\mathrm{t}}=\mathrm{a} \mathrm{W}_{\mathrm{t}}^{0.82}$ we get

$$
R_{t}=a W_{o}^{0.82} e^{0.82 \mathrm{Gt}}
$$

The respiration integral, by analogy to the biomass integral, is given by:

$$
\begin{array}{r}
\mathrm{R}^{\mathrm{x}}=\mathrm{a} \mathrm{N}_{\mathrm{o}} \mathrm{W}_{\mathrm{o}}^{0.82} \cdot \int_{0}^{\mathrm{T}} \mathrm{e}^{(0.82 \mathrm{G}-\mathrm{z}) \mathrm{t}} \mathrm{dt} \\
\mathrm{R}^{\mathrm{x}}=\mathrm{a}\left(\left[\mathrm{N}_{\mathrm{T}} \mathrm{W}_{\mathrm{T}}^{0.82}-\mathrm{N}_{\mathrm{o}} \mathrm{W}_{\mathrm{o}}^{0.82}\right] /,[0.82 \mathrm{G}-\mathrm{Z}]\right)
\end{array}
$$

This respiration is compensated for temperature effects by the same factor as was obtained for females carrying eggs.

For the conversion of dry weights to energy units we used the following conversion factors: $11 \mathrm{O}_{2}$ consumed is assumed equivalent to $0.4 \mathrm{~g} \mathrm{C}$ metabolized (Crisp, 1971); $1 \mathrm{~g} \mathrm{C}=45.8 \mathrm{~kJ}$ (= $10.92 \mathrm{kcal}$ ) (Salonen et al., 1976), and organic carbon is $52 \%$ of ash free dry weight (Salonen et al., 1976).

All production estimates given in the text are production over the study period of $99 \mathrm{~d}$.

\section{RESULTS}

The raw data (i.e. counts $6.06 \mathrm{~cm}^{-2}$ of the different stages) are given in Table 1. Mean dry weight of the stages, and geometric mean weight of consecutive stages are given in Table 2. Fig. 1(a-f) shows the density curves of copepodite and adult stages (running means), with the combined fitted Gaussian distributions superimposed. We found 3 generations during the study period, well distinguished in the first stages, but gradually more overlapping in the older ones.

For calculations of the stage duration with Rigler and Cooley's (1974) method it is necessary to draw a smooth curve on a plot of mean pulse times against stage numbers. Rigler and Cooley (1974) advise performing the smoothing in such a way that each stage is longer than the preceding one, and that negative mortality is minimal. Fig. 2 shows the effect of this smoothing. The only important modification is that the smoothed mean pulse time $\mu_{s}$ of Copepodite IV in the first peak is shifted forward. There is no negative mortality. The resulting stage durations and the number of copepods in each stage are shown in Table 3. A problem is posed by the adult stage. The method of Rigler and Cooley (1974) implies that all mortality occurs at the transition of one stage to the next. This assumption does not lead to serious bias as long as the stages are of short duration, but when they last longer and there is considerable mortality (as in the adult stage, where all individuals eventually die) it results in a relative forward shift of the mean pulse time. Therefore the mean pulse time of the adults is not reliable as a basis for the estimation of its duration. Fortunately there is almost no somatic growth between Copepodite $V$ and adults. The assumption that all Copepodite $\mathrm{V}$ become adult therefore introduces only 
Table 1. Tachidius discipes. Original counts (No. $6.06 \mathrm{~cm}^{-2}$ ) on which the production estimates were based. CI, ... CV: Copepodites 1 to 5; AD; total number of adults; FCE: number of females carrying eggs

\begin{tabular}{|c|c|c|c|c|c|c|c|}
\hline Date & $\mathrm{Cl}$ & CII & CIII & CIV & $\mathrm{CV}$ & $A D$ & FCE \\
\hline 21.3 .79 & 0 & 0 & 0 & 0 & 0 & 2 & 1 \\
\hline 24.3 .79 & 0 & 0 & 1 & 0 & 1 & 2 & 1 \\
\hline 27.3 .79 & 1 & 1 & 0 & 1 & 2 & 12 & 3 \\
\hline 30.3 .79 & 3 & 0 & 1 & 1 & 1 & 10 & 2 \\
\hline 2. 4.79 & 6 & 3 & 0 & 2 & 2 & 7 & 1 \\
\hline 5. 4.79 & 0 & 2 & 2 & 1 & 2 & 17 & 6 \\
\hline 8. 4.79 & 9 & 14 & 10 & 1 & 0 & 8 & 3 \\
\hline 14.4 .79 & 1 & 3 & 2 & 3 & 8 & 11 & 0 \\
\hline 17.4 .79 & 1 & 7 & 0 & 6 & 10 & 13 & 1 \\
\hline 20.4 .79 & 11 & 20 & 29 & 27 & 21 & 24 & 3 \\
\hline 23.4 .79 & 22 & 15 & 13 & 13 & 17 & 39 & 8 \\
\hline 29.4 .79 & 55 & 52 & 62 & 37 & 17 & 4 & 1 \\
\hline 2. 5.79 & 14 & 21 & 27 & 17 & 25 & 57 & 8 \\
\hline 5.5 .79 & 11 & 23 & 35 & 60 & 73 & 85 & 12 \\
\hline 8.5 .79 & 25 & 15 & 34 & 52 & 40 & 101 & 19 \\
\hline 11.5 .79 & 22 & 16 & 13 & 41 & 54 & 152 & 32 \\
\hline 14.5 .79 & 31 & 41 & 41 & 31 & 19 & 92 & 34 \\
\hline 17.5 .79 & 50 & 40 & 30 & 23 & 39 & 191 & 96 \\
\hline 20.5 .79 & 22 & 26 & 39 & 43 & 39 & 131 & 68 \\
\hline 23.5 .79 & 1 & 5 & 5 & 10 & 9 & 56 & 13 \\
\hline 26.5 .79 & 1 & 0 & 1 & 1 & 6 & 62 & 26 \\
\hline 29.5 .79 & 8 & 1 & 4 & 5 & 12 & 98 & 30 \\
\hline 1. 6.79 & 1 & 2 & 1 & 1 & 0 & 44 & 15 \\
\hline 4.6 .79 & 0 & 0 & 0 & 0 & 0 & 26 & 5 \\
\hline 7.6 .79 & 0 & 0 & 1 & 1 & 2 & 28 & 9 \\
\hline 10. 6.79 & 0 & 0 & 0 & 1 & 0 & 76 & 21 \\
\hline 13.6 .79 & 0 & 0 & 1 & 0 & 1 & 42 & 7 \\
\hline 19.6 .79 & 1 & 0 & 1 & 2 & 1 & 7 & 4 \\
\hline 25.6 .79 & 3 & 0 & 3 & 0 & 1 & 11 & 5 \\
\hline
\end{tabular}

Table 2. Tachidius discipes. Dry weights $\mathrm{W}_{1}$ of copepodite stages. $\mathrm{N}=$ number of copepods weighted in a batch. $\left(\mathrm{W}_{\mathrm{i}} \mathrm{W}_{1+1}\right)^{1 / 2}=$ geometric mean of the weights of 2 consecutive stages

\begin{tabular}{|lrcc|}
\hline Stage & $N$ & $\mathrm{~W}_{1}(\mu \mathrm{g})$ & $\left(\mathrm{W}_{\mathrm{i}} \mathrm{W}_{\mathrm{i}+1}\right)^{1 / 2}$ \\
\hline COP I & 50 & 0.20 & 0.23 \\
COP II & 54 & 0.26 & 0.34 \\
COP III & 108 & 0.45 & 0.60 \\
COP IV & 70 & 0.80 & 1.18 \\
COP V & 68 & 1.73 & 1.76 \\
AD & 325 & 1.80 & \\
Egg sac & 60 & 0.43 & \\
\hline
\end{tabular}

a very light bias, and circumvents the tricky problem of estimating adult-stage duration. The production of copepodites and adults thus calculated is $1.57 \mathrm{~g}$ dwt $\mathrm{m}^{-2}$. This value includes the production of the biomass entering the copepodite stage as Copepodite I (see 'Material and Methods'): this amount of $0.47 \mathrm{~g}$ $\mathrm{dwt} \mathrm{m}^{-2}$ is better included in the naupliar production. $\mathrm{P}_{\mathrm{c}}$, the production of copepodites and adults, is then

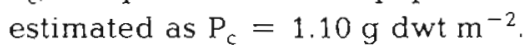

Table 3. Tachidius discipes. Duration (D) of copepodite stages and number of copepods recruited to the stage for the 3 peaks in spring 1979, determined by the method of Rigler and Cooley $\left(19^{\circ} 4\right)$

\begin{tabular}{|clcc|}
\hline Stage & $\begin{array}{c}\text { Duration } \\
\text { (d) }\end{array}$ & $\begin{array}{c}\text { Recruitment } \\
\left.\text { (per } 10 \mathrm{~cm}^{2}\right)\end{array}$ \\
\hline \multirow{5}{*}{ 1st peak } & COP I & 0.85 & 79 \\
& COP II & 2.15 & 69 \\
& COP III & 1.85 & 62 \\
& COP IV & 8.15 & 55 \\
& COP V & 9.85 & 49 \\
& COP I & 0.50 & 1615 \\
& COP II & 1.50 & 563 \\
& COP III & 2.50 & 434 \\
& COP IV & 4.00 & 277 \\
& COP V & 6.00 & 211 \\
& COP I & 0.90 & 635 \\
& COP II & 1.10 & 600 \\
3rd peak & COP III & 1.30 & 536 \\
& COP IV & 1.30 & 302 \\
& COP V & 1.70 & 175 \\
\hline
\end{tabular}



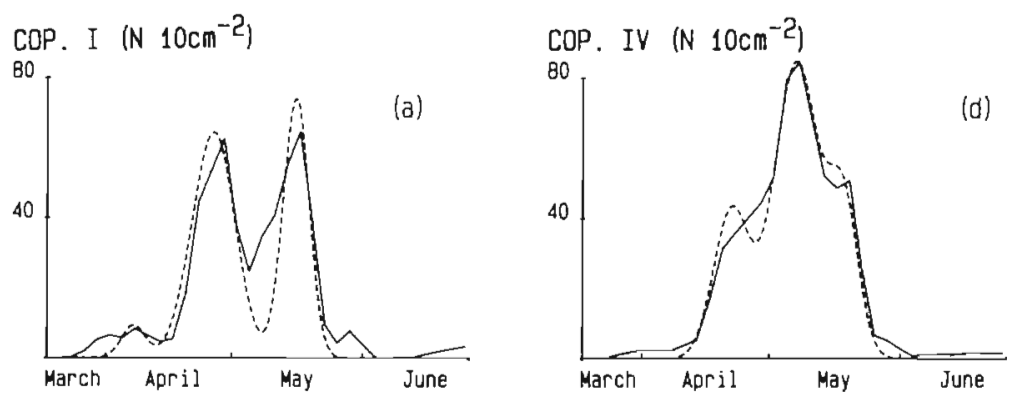

Fig. 1. (a-f): Tachidius discipes. Densities (N $\left.10 \mathrm{~cm}^{-2}\right)$ of copepodite stages I (a), II (b), III (c), IV (d), V (e) and of the adults (f) in a brackish water pond during the spring of 1979. Full lines: trendline (see text) through observations. Broken lines: combined Gaussians fitted to the data
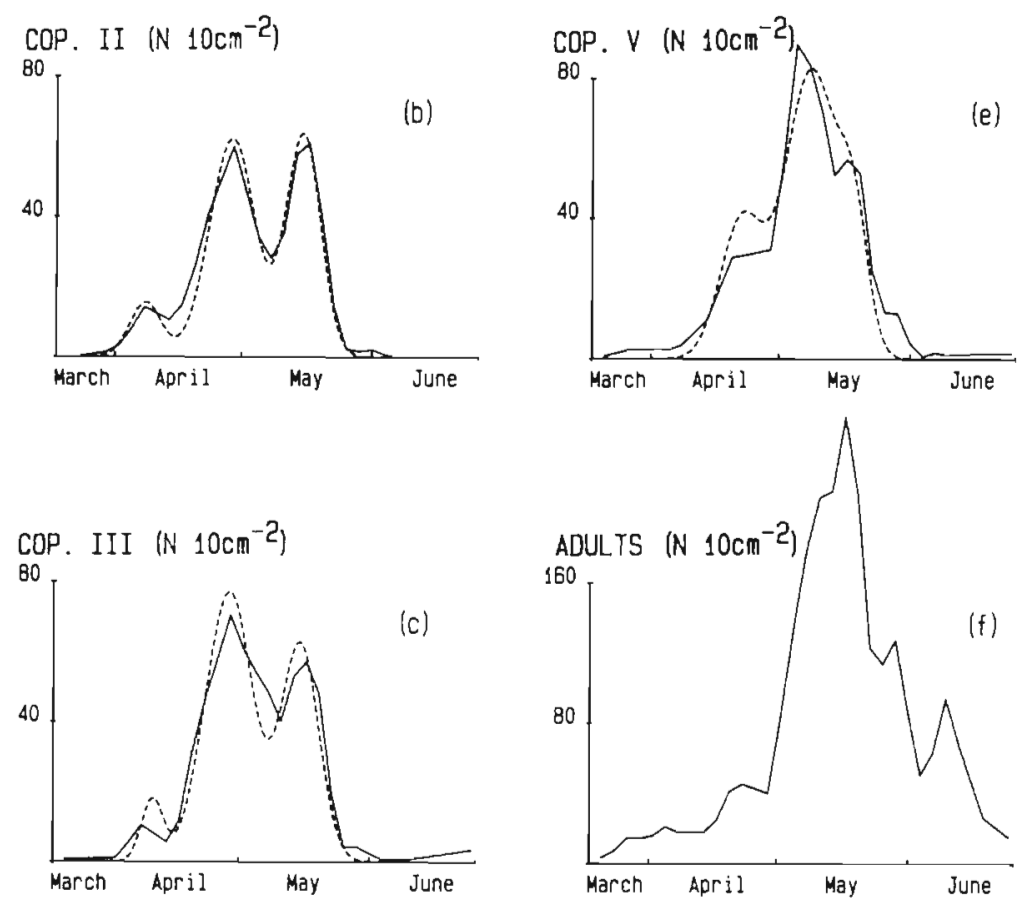

Table 4 gives the production estimation with the size-frequency method. The $\mathrm{P}_{\mathrm{c}}$ corrected for Copepodite I production by the value $0.47 \mathrm{~g} \mathrm{dwt} \mathrm{m}^{-2}$ (of the previous estimate) is: $P_{c}=1.02 \mathrm{~g} \mathrm{dwt} \mathrm{m}^{-2}$.

Table 4. Tachidius discipes. Production estimation by the size-frequency method. $a_{1}=$ relative duration of Stage $j$ (where $a_{1}=$ arbitrarily chosen as 1 ); $\bar{n}_{j}=$ mean number of copepods in Stage $j_{;} \mathrm{N}_{\mathrm{j}}=$ an estimate of the recruitment into Stage $j, P_{j}$ ' of the production of Stage $j$

\begin{tabular}{|c|c|c|c|c|}
\hline Stage & $a_{j}$ & $\overline{\mathrm{n}}_{\mathrm{j}}$ & $\mathrm{N}_{\mathrm{j}}$ & ${ }^{\prime} P_{j}$ \\
\hline COP I & 1 & 17.13 & 1199.36 & 28.50 \\
\hline COP II & 1.14 & 17.49 & 1074.36 & 50.26 \\
\hline COP III & 1.53 & 20.26 & 927.38 & 90.53 \\
\hline COP IV & 1.86 & 20.63 & 776.50 & 182.11 \\
\hline COP V & 2.24 & 21.49 & 621.65 & 137.01 \\
\hline \multirow[t]{2}{*}{$\mathrm{AD}$} & 9.43 & 73.27 & 544.03 & 995.56 \\
\hline & $\overline{17 . \overline{38}}$ & & & $\overline{1483.98}$ \\
\hline
\end{tabular}

Egg production, estimated by Eq. (2) is: $P_{e}=0.31 \mathrm{~g}$ $\mathrm{dwt} \mathrm{\textrm {m } ^ { - 2 }}$. Number of eggs produced is $29,16110 \mathrm{~cm}^{-2}$.

Naupliar production, estimated by Eq. (5) is: $P_{n}=$ $1.11 \mathrm{~g} \mathrm{dwt} \mathrm{m}^{-2}$.

Total production amounts to $2.52 \mathrm{~g} \mathrm{dwt} \mathrm{m}^{-2}$ and $2.44 \mathrm{~g} \mathrm{dwt} \mathrm{m}^{-2}$, depending on whether the first or second estimate of $P_{c}$ is used.

Duration of the copepodite stages is 23, 14.5 and $7.5 \mathrm{~d}$ for the 3 peaks. Duration of the naupliar stage is about half that of the copepodite stage (Smol and Heip, 1974). Using this experimentally obtained ratio, the duration of the naupliar phase is estimated to be $8 \mathrm{~d}$. The biomass integral $\mathrm{B}^{\mathrm{x}}$ for the nauplii then becomes: $\mathrm{B}^{\mathrm{x}}=2.96 \mathrm{~g} \mathrm{dwt} \times$ days $\times \mathrm{m}^{-2}$. The biomass integral for copepodites, adults and eggs is $22.77 \mathrm{~g}$ dwt $\times$ days $\times \mathrm{m}^{-2}$. Mean biomass $\overline{\mathrm{B}}=25.73 / 99=0.26 \mathrm{~g} \mathrm{dwt} \mathrm{m}^{-2}$. $\mathrm{P} / \overline{\mathrm{B}}$ is 9.7 over the study period, or 3.2 generation $^{-1}$.

Respiration of copepodites and adults is estimated as $\mathrm{R}_{\mathrm{c}}=3.3 \mathrm{l} \mathrm{O}_{2} \mathrm{~m}^{-2}$ over the sampling period. Their production efficiency is 0.30 . 

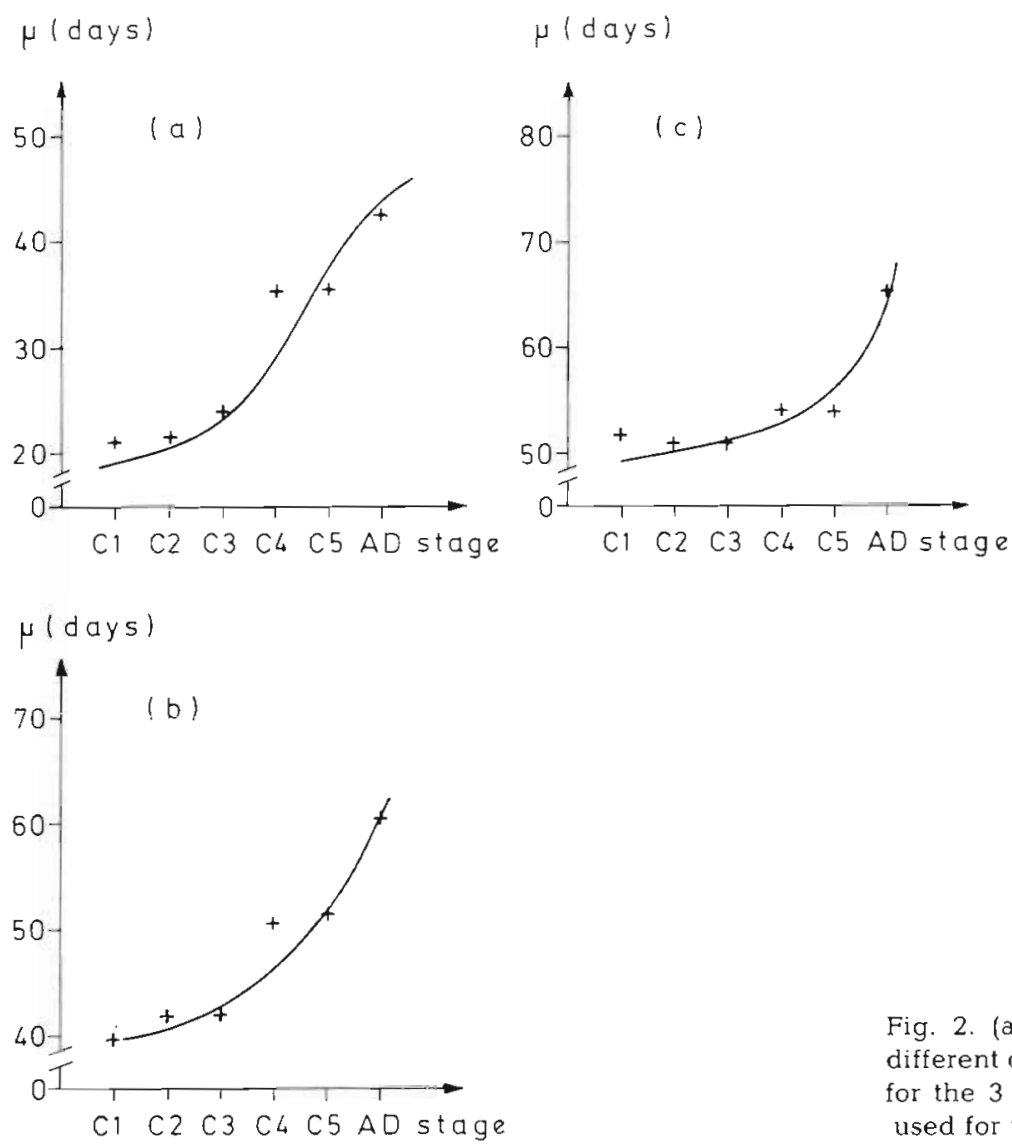

Fig. 2. $(\mathrm{a}-\mathrm{c})$ : Tachidius discipes. Mean pulse times of the different developmental stages plotted against stage numbers for the 3 peaks in the spring of 1979 . The smooth lines are used for the application of Rigler \& Cooley's (1974) method

When egg production is attributed to the adult population, production efficiency becomes 0.36 . With an estimated naupliar respiration of $1.121 \mathrm{O}_{2} \mathrm{~m}^{-2}$ (Eq. [9]), the production efficiency of the total population is calculated as 0.43 .

\section{DISCUSSION}

Tachidius discipes produced 3 generations in spring 1979. In a $5 \mathrm{~d}$ interval sampling in 1980 (essentially aimed at another population) we could distinguish the same pattern. It was, as a whole, shifted to 10 to $12 \mathrm{~d}$ later.

Therefore we suppose this pattern occurs consistently each year. Previously, it was not revealed by Heip (1980) in fortnightly samples with all copepodite stages pooled. One single peak was described, and it was concluded that growth is slower under natural conditions than in laboratory cultures. It is shown here that sampling intervals should be very short, and that the copepods should be subdivided into short-living stages in order to reveal the dynamics of a rapidly developing population such as Tachidius discipes.

We estimated the production in 2 different ways, each characterized by a number of simplifying assumptions. In the first method, the smoothing of the mean pulse times may well be the most critical step, especially in Copepodites IV and V. Because of the bias, possibly introduced by this extensive data handling, we made a second, independent estimate. This has a weakness in the assumption of a constant mortality rate in all copepodite stages. Both estimates are relatively close to one another, though. This adds some confidence to our estimates.

Due to the rapid development, the production of Tachidius discipes is relatively high. The species is

Table 5. P/B of meiobenthic crustaceans determined from field observations

\begin{tabular}{|lrl|}
\hline \multicolumn{1}{|c}{ Species } & $\begin{array}{c}\mathrm{P} / \mathrm{B} \\
\left(\mathrm{yr}^{-1}\right)\end{array}$ & Source \\
\hline & 3.6 & Feller (1982) \\
Huntemannia jadensis & 18.0 & Fleeger \& Palmer (1982) \\
Microarthridion littoralis & 2.7 & Herman et al. (1983) \\
Cypridejs torosa & 34.3 & This study \\
Tachidius discipes & & \\
\hline
\end{tabular}


only found during spring in this habitat. Expressing the $\mathrm{P} / \overline{\mathrm{B}}$ on a yearly base by changing the time dimension, it becomes $\mathrm{P} / \overline{\mathrm{B}}=35 \mathrm{yr}^{-1}$. Compared to other meiobenthic populations for which direct production estimates have been made, this is very high (Table 5). It should be kept in mind here that $T$. discipes does not realize this high productivity. As it is restricted in appearance to the most favourable season, many 'maintenance costs' experienced by other species in adverse seasons, are probably less important to this species. Therefore the value $\mathrm{P} / \overline{\mathrm{B}}=35 \mathrm{yr}^{-1}$ is of limited significance. Only when the mean biomass would be estimated from samples, regularly spaced over a full year, this biomass would have to be multiplied by 35 to find the yearly production.

The production efficiency of Tachidius discipes is much higher than $21 \%$, the mean value given by Humphreys (1979) for non-insect invertebrate herbivores. It is nearly equal to $39 \%$, the mean value for non-social insect herbivores, and it also approaches the mean for non-insect invertebrate detritivores $(36 \%)$. The formation of the 2 groups 'non-social insects' and 'non-insect invertebrates' was the best possible statistical inference Humphreys (1979) could make on the basis of the existing data. In these data certain taxonomical (and probably also ecological) groups are overemphasized, whereas others are almost unstudied. It is highly improbable that the grouping in non-social insects and non-insect invertebrates will remain unchanged when more data are accumulated. Anyway, $T$. discipes has a production efficiency very near to that of the non-social insects, to which it is both taxonomically and ecologically more akin than to the molluscs, which constitute the bulk of Humphreys' non-insect invertebrates.

It must be noted here that Banse (1979) did not find differences in production efficiency according to the species' weight at maturity, longevity or feeding type. He used a limited, but more critically selected data base. When sample size is small, it is, of course, difficult to prove the existence of significant differences. Nevertheless, Banse's (1979) study indicates that the differences between groups in Humphreys (1979) could, at least in part, also be due to different methodologies used in the study of different groups. This is an important ecological question which requires further study.

The production efficiency calculated here is considerably lower than the value calculated by Warwick (1981) for the same species. This discrepancy is entirely due to the combination of field data and respiration data from 2 different populations. Table 6 lists the efficiencies for different temperatures using Warwick's calculation method, with the appropriate respiration data. That calculation is performed for an expo-
Table 6. Tachidius discipes. Production efficiency calculated from culturing data of Heip and Smol (1976)

\begin{tabular}{|cccc|}
\hline Temp. $\left({ }^{\circ} \mathrm{C}\right)$ & $P\left(J . J^{-1} \mathrm{~d}^{-1}\right)$ & $R\left(J . J^{-1} \mathrm{~d}^{-1}\right)$ & $\mathrm{P} /(\mathrm{P}+\mathrm{R})$ \\
\hline 5 & 0.036 & 0.086 & 0.30 \\
10 & 0.086 & 0.122 & 0.41 \\
15 & 0.136 & 0.180 & 0.43 \\
20 & 0.186 & 0.259 & 0.42 \\
25 & 0.236 & 0.374 & 0.39 \\
\hline
\end{tabular}

nentially increasing population, with stable age distribution, where the production per unit biomass is estimated as $r_{m}$ the intrinsic rate of natural increase. (A more consistent measure of it is the birth rate $b$, which, however, is not known for Tachidius discipes, and will not be much higher than $r_{m}$ in an exponentially increasing population with little mortality and a short generation time.) The population structure in the field is clearly different from a stable age distribution, and obviously the mortality is quite important. Nevertheless, the production efficiency found in this study is exactly equal to the predicted value of $43 \%$ at $15{ }^{\circ} \mathrm{C}$. This corroborates the findings of Woodland and Cairns (1980) that, given certain parameters (respiration rate, longevity, ratio final : initial weight), the production efficiency is almost independent of the precise population age structure within the rather wide limits of 'biologically reasonable' mortality patterns.

Acknowledgements. P. Herman and C. Heip acknowledge a grant of the Belgian National Foundation for Scientific Research (NFWO). Part of this research was supported by the Belgian Ministry of Science Policy (Concerted Actions Oceanography). We thank W. Gijselinck for practical assistance.

\section{LITERATURE CITED}

Allen, K. R. (1971). Relation between production and biomass. J. Fish. Res. Bd Can. 28: 1573-1581

Banse, K. (1979). On weight dependence of net growth efficiency and specific respiration rates among field populations of invertebrates. Oecologia (Berl.) 38: 111-126

Banse, K. (1982). Mass-scaled rates of respiration and intrinsic growth in very small invertebrates. Mar. Ecol. Prog. Ser. 9: 281-297

Banse, K., Mosher, S. (1980). Adult body mass and annual production/biomass relationships of field populations. Ecol. Monogr. 50: 355-379

Bhattacharya, C. G. (1967). A simple method of resolution of a distribution into Gaussian components, Biometrics 23: 115-135

Crisp, D. J. (1971). Energy flow measurements. In: Methods for the study of marine benthos. IBP Handbook No. 16. Blackwell Scientific Publications, Oxford, p. 197-279

De Jonge, V. N., Bouwman, L. A. (1977). A simple density separation technique for quantitative isolation of meiobenthos using the colloidal silica Ludox-TM. Mar Biol. 42: $143-148$ 
Feller, R. J. (1982). Empirical estimates of carbon production for a meiobenthic harpacticoid copepod. Can. J. Fish. aquat. Sci. 39: 1435-1443

Fleeger, J. W. Palmer, M. A. (1982). Secondary production of the estuarine meiobenthic copepod Microarthridion littorale. Mar. Ecol. Prog. Ser. 7: 157-162

Gerlach, S. A. (1971). On the importance of marine meiofauna for benthos communities. Oecologia (Berl.) 6: 176-190

Heip, C. (1977). On the evolution of reproductive potentials in a brackish water meiobenthic community. Mikrofauna Meeresboden 61: 105-112

Heip, C. (1979). Density and diversity of meiobenthic copepods: the oscillatory behaviour of population and community parameters. In: Naylor, E., Hartnoll, R. G. (ed.) Cyclic phenomena in marine plants and animals. Pergamon Press, Oxford, New York, p. 43-47

Heip, C. (1980). The influence of competition and predation on production of meiobenthic copepods. In: Tenore, K. R., Coull, B. C. (ed.) Marine benthic dynamics. The Belle W Baruch Library in Marine Science, No. 11. University of South Carolina Press, Columbia, p. 167-177

Heip, C., IJerman, D. M. J., Coomans, A. (1982). The productivity of marine meiobenthos. Academiae Analecta 44: $1-20$

Heip, C., Smol, N. (1976). Influence of temperature on the reproductive potential of two brackish-water harpacticoids (Crustacea, Copepoda). Mar. Biol. 45: 255-260

Heip, C., Smol, N., Hautekiet, W. (1974). A rapid method for extracting meiobenthic nematodes and copepods from mud and detritus. Mar. Biol. 28: 79-81

Herman, P. M. J., Heip, C. (1982). Growth and respiration of Cyprideis torosa Jones 1850 (Crustacea, Ostracoda). Oecologia (Berl.) 54: 300-303

Herman, P. M. J., Heip, C. (1983). The respiration of five brackish-water harpacticoid species. J exp. mar Biol. Ecol. 71: 249-256

Herman, P. M. J., Heip, C. (in press). Long-term dynamics of meiobenthic populations. Oceanologica Acta

Herman, P. M. J., Heip, C., Vranken, G. (1983). The production of Cyprideis torosa Jones 1850 (Crustacea, Ostracoda). Oecologia (Berl.) 58: 326-331

Humphreys, W. F. (1979). Production and respiration in animal populations. J. Anim. Ecol. 48: 427-453
Muus, B. J. (1967). The fauna of Danish estuaries and lagoons Distribution and ecology of dominating species in the shallow reaches of the mesohaline zone. Meddr Danm Fisk-og. Havunders. 5: 1-316

Rigler, F. H., Cooley, J. M. (1974). The use of field data to derive population statistics of multivoltine copepods. Limnol. Oceanogr. 19: 636-655

Salonen, K., Sarvala, J., Hakala, I., Viljanen, M. (1976). The relation of energy and organic carbon in aquatic invertebrates. Limnol. Oceanogr. 21: 724-730

Schiemer, F. (1982a). Food dependence and energetics of freeliving nematodes I. Respiration, growth and reproduction of Caenorhabditis briggsae (Nematoda) at different levels of food supply. Oecologia (Berl.) 54: 108-121

Schiemer, F. (1982b). Food dependence and energetics of freeliving nematodes. II. Life history parameters of Caenorhabditis briggsae (Nematoda) at different levels of food supply. Oecologia (Berl.) 54: 122-128

Schiemer, F., Duncan, A., Klekowski, R. Z. (1980). A bioenergetic study of a benthic nematode, Plectus palustris de Man 1880, throughout its life cycle. Oecologia (Berl.) 44: 205-212

Smol, N., Heip, C. (1974). The culturing of some harpacticoid copepods from brackish water. Biol. Jb. Dodonaea 42 159-169

Teare, M. (1978). Post-embryonic development of Tachidius discipes Giesbrecht 1881 (Copepoda, Harpacticoida). Cah. Biol. mar. 19: 343-353

Teare, M., Price, R. (1979). Respiration of the meiobenthic harpacticoid copepod, Tachidius discipes from an estuarine mudflat. J. exp. mar. Biol. Ecol. 41: 1-8

Velleman, P. F. (1977). Robust nonlinear data smoothers: definitions and recommandations. Proc. natr. Acad. Sci. U.S.A. $74: 434-436$

Warwick, R. M. (1981). The influence of temperature and salinity on energy partitioning in the marine nematode Diplolaimelloides bruciei. Oecologia (Berl.) 51: 318-325

Winberg, G. (1971). Methods for the estimation of production of aquatic animals. Academic Press, London, New York

Woodland, D. J., Cairns, S. C. (1980). Sensitivity of population energy efficiency indices to differences in mortality rates Oecologia (Berl.) 46: 214-216 